\title{
Tamanho da leitegada e pesos médios, ao nascer e aos 21 dias de idade, de leitões da raça Large White
}

[Litter size and average weights at birth and at 21 days of age of Large White piglets]

\author{
M.C.R. Holanda ${ }^{1}$, S.B.P. Barbosa ${ }^{2}$, I.B.M. Sampaio ${ }^{3}$, E.S. Santos $^{4}$, K.R. Santoro ${ }^{5}$ \\ ${ }^{1}$ Departamento de Zootecnia - FUNESA \\ Rua Dom Manoel de Medeiros, s/n - Dois Irmãos \\ 52171-900 - Recife, PE \\ ${ }^{2}$ Departamento de Zootecnia - UFRPE \\ ${ }^{3}$ Departamento de Zootecnia - UFMG \\ ${ }^{4}$ Departamento de Estatística e Informática - UFRPE \\ ${ }^{5}$ Colegiado de Zootecnia - UNIVASF
}

\begin{abstract}
RESUMO
Avaliaram-se os efeitos da época de parto e idade da matriz ao parto (IMP) sobre o tamanho da leitegada (TL), da época de parto, idade da matriz ao parto e tamanho da leitegada sobre o peso médio ao nascer (PMN), e da época de parto, idade da matriz ao parto, número de nascidos vivos (NV) e percentual de machos na leitegada (PERCM) sobre o peso aos 21 dias de idade (PM21) de leitões Large White. Utilizaram-se dados de 3259 leitões nascidos no período de junho/85 a junho/96. A avaliação foi feita por meio de regressão múltipla. Para TL apenas o efeito de IMP determinou modificações significativas sobre o número de leitões nascidos. TL médio foi $9,73 \pm 2,78$, observando-se maiores leitegadas em fêmeas de 2,84 a 3,83 anos. PMN e PM21 foram $1,35 \mathrm{~kg} \pm 0,18$ e 5,06 $\mathrm{kg} \pm 1,00$, respectivamente. Para PMN foram significativos os efeitos de IMP e TL, com redução do peso em 20g para cada leitão adicional. Para PM21 apenas o número de NV apresentou efeito significativo.
\end{abstract}

Palavras-chave: eficiência reprodutiva, idade da matriz, leitões, percentual de machos, tamanho de leitegada

\begin{abstract}
The effects of season of birth (PE) and age of sow at birth (IMP) on litter size (TL); season of birth, age of sow and litter size on average weight at birth (PMN); season of birth age of sow, number of alive piglets at birth (NV), and percentage of alive males on average weight at 21 days of age (PM21) of 3259 Large White piglets born from June/85 to June/96 were evaluated by multiple regression analyses. The IMP effect on TL was significant. The average TL was 9.73 \pm 2.78 . Larger litters were observed for sows from 2.84 to 3.83 years of age. The average $P M N$ and $P M 21$ were $1.35 \mathrm{~kg} \pm 0.18$ e $5.06 \mathrm{~kg} \pm 1.00$, respectively. The IMP and TL effects on PMN traits were linear and significant. A decrease of $20 \mathrm{~g}$ on piglet weight was estimated for each additional piglet in the litter. The effect of $N V$ was significant only for PM21 trait.
\end{abstract}

Keywords: reproductive efficiency, age of the head office, pig, percentile of male, litter size

Recebido para publicação em 15 de outubro de 2003

Recebido para publicação, após modificações, em 5de julho de 2004

E-mail: holandamcr@click21.com.br 


\section{INTRODUÇÃO}

Identificar as causas do baixo desempenho em granjas de suínos e elevar a sua produtividade é meta da suinocultura competitiva e sustentável. Para tanto, a existência de alvos de produtividade para o rebanho constitui-se em elemento essencial para o monitoramento do desempenho do sistema e para o diagnóstico de problemas de produção.

A genética de suínos no Brasil é uma das mais avançadas e ainda reúne condições ambientais compatíveis àquelas exigidas pela criação, tendose como aumentar a produção e melhorar a produtividade (Gomes et al., 1992). O aumento das eficiências produtiva e reprodutiva torna-se, portanto, ainda mais necessário em uma região como a Nordeste, que, mesmo não tendo a influência européia de criação de suínos e a concentração de indústrias que dêem suporte à produção, como na região Sul, possui $23,3 \%$, dos 38 milhões de cabeças alojadas no país (Anuário..., 2002). O Nordeste é a segunda região brasileira de concentração de suínos, em representação numérica (Associação..., 2003), sendo de grande importância social e econômica para a região.

O desejável não é apenas que o número de leitões nascidos seja grande, mas convém que haja a vantagem de maior porcentagem de leitões criados. De acordo com Sobestiansky et al. (1998), a medida mais utilizada para avaliação do desempenho do rebanho de reprodução é o número de leitões desmamados/fêmea/ano, e os principais fatores influenciadores são a idade média das fêmeas, a época de parição, a genética, a nutrição (pré-cobrição), as doenças reprodutivas e o manejo das cobrições.

O tamanho da leitegada ao desmame é influenciado pelo número de leitões nascidos vivos (Siewerdt e Rech,1991). A idade da matriz ao parto e/ou ordem de parição, a época do parto e o número ou percentual de machos interferem no tamanho da leitegada (Alves et al., 1987; Dierckx et al., 1996). O peso da leitegada, tanto ao nascer como aos 21 dias de idade, também é influenciado pela idade da matriz ao parto (Pinheiro et al., 1996b), época de parto (Simplício et al., 1990; Freitas et al., 1992) e tamanho da leitegada (Mores, 1993).
O trabalho teve como objetivo identificar os principais fatores de natureza não genética que influenciam o tamanho da leitegada ao nascer e os pesos médios ao nascer e aos 21 dias de idade, em leitões da raça Large White, criados em granja comercial no Estado de Pernambuco.

\section{MATERIAL E MÉTODOS}

Foram utilizadas informações de 3259 leitões, provenientes de 335 leitegadas da raça Large White, nascidos no período de junho/85 a junho/96 inclusive, de uma criação de suínos em São Lourenço da Mata, Pernambuco. O plantel estudado era formado por animais puros de origem, e todas as informações produtivas foram repassadas ao Pig-Book Brasileiro.

As matrizes, até a confirmação da prenhez, ficavam alojadas em baias coletivas de até cinco fêmeas. Ao final dos 28 a 30 dias após a cobrição, as fêmeas eram novamente expostas ao reprodutor para confirmação da prenhez. Após confirmação, eram transferidas para o galpão de gestação e mantidas em gaiolas individuais. Nesse galpão, as fêmeas prenhes eram alimentadas com $2 \mathrm{~kg} /$ dia de ração de reprodução e água ad libitum.

De 10 a 14 dias antes do parto, as matrizes eram vermifugadas, lavadas e conduzidas à maternidade, devidamente preparada para recebê-las.

As fêmeas permaneciam até 21 dias após o parto nas celas parideiras, sendo então remanejadas dentro da própria instalação, para baias coletivas, mantendo-se duas fêmeas por baia, com suas respectivas leitegadas, até o dia do desmame, realizado sempre ao $30^{\circ}$ dia após o parto. Os leitões, no primeiro dia de vida, eram marcados (sistema australiano de marcação) e tinham os dentes cortados. Ao terceiro dia, recebiam, via intramuscular, aplicação de ferro dextrano e, aos 21 dias de idade (desmame), eram colocados em creches coletivas com gaiolas suspensas.

A idade da matriz forneceu melhor referencial de avaliação, por isso resolveu-se utilizá-la em lugar da ordem de parição, pois uma mesma ordem de parto poderia ser verificada em fêmeas com idades diferentes. Além disso, não se conheciam todas as ordens de parto das matrizes do plantel e, como o objetivo do estudo foi justamente 
avaliar a idade, optou-se por trabalhar com essa variável.

Trabalhou-se com apenas duas épocas de parição, definidas como seca (setembro a fevereiro - temperatura média compensada: $26,1^{\circ} \mathrm{C}$; umidade relativa do ar: $75,3 \%$; precipitação mensal média: $83,6 \mathrm{~mm}^{3}$ ) e chuvosa (março a agosto - temperatura média compensada: $25,7^{\circ} \mathrm{C}$; umidade relativa do ar: $83 \%$; precipitação pluviométrica mensal média: $327,2 \mathrm{~mm}^{3}$ ).

Para o estudo do tamanho da leitegada, usou-se regressão múltipla, utilizando-se o programa SAS (Software..., 1996).

Para tamanho da leitegada, o modelo de regressão foi: $\hat{Y}_{\mathrm{i}}=\mathrm{a}+\mathrm{b}_{1} \mathrm{X}_{1}+\mathrm{b}_{2} \mathrm{X}_{2}+\mathrm{b}_{3} \mathrm{X}_{3}$ (equação 1), em que:

$\mathrm{a}=$ intercepto;

$b_{1}, b_{2}, b_{3}=$ coeficientes de regressão parcial de $X$ sobre Y;

$\mathrm{X}_{1}=$ efeito da época de parição (sendo $\mathrm{i}=1$ set a fev e $\mathrm{i}=2$ mar a ago);

$\mathrm{X}_{2}=$ efeito linear da idade da matriz ao parto, em anos $(0,84$ a 6,25$)$;

$\mathrm{X}_{3}=$ efeito quadrático da idade da matriz ao parto.
Para peso ao nascer, o modelo foi: $\hat{\mathrm{Y}}_{\mathrm{i}}=\mathrm{a}+\mathrm{b}_{1} \mathrm{X}_{1}+\mathrm{b}_{2} \mathrm{X}_{2}+\mathrm{b}_{3} \mathrm{X}_{3}+\mathrm{b}_{4} \mathrm{X}_{4}$ (equação 2), em que:

$\mathrm{b}_{4}=$ coeficiente de regressão parcial de $\mathrm{X}$ sobre $\mathrm{Y}$;

$\mathrm{X}_{4}=$ efeito do tamanho da leitegada (2 a 17).

Para peso aos 21 dias, o modelo foi: $\hat{\mathrm{Y}}_{\mathrm{i}}=\mathrm{a}+\mathrm{b}_{1} \mathrm{X}_{1}+\mathrm{b}_{2} \mathrm{X}_{2}+\mathrm{b}_{3} \mathrm{X}_{3}+\mathrm{b}_{4} \mathrm{X}_{4}$ (equação 3), em que:

$\mathrm{X}_{3}=$ efeito do número de leitões nascidos vivos (2 a 15);

$\mathrm{X}_{4}=$ efeito do percentual de machos na leitegada (0 a 90).

\section{RESULTADOS E DISCUSSÃO}

O tamanho da leitegada (vivos e mortos) variou de 2 a 17, média de 9,73 $\pm 2,78$ leitões (Tab. 1), menor que a nacional para a raça Large White, de 11,05 leitões (Associação..., 2003).

Informações produtivas e reprodutivas, estudos de correlação simples e estatística descritiva das variáveis analisadas encontram-se nas Tab. 2 e 3.

Tabela 1. Informações produtivas e reprodutivas de leitões da raça Large White ao nascer e aos 21 dias de idade, no período de 1985 a 1996

\begin{tabular}{lcc}
\hline \multirow{2}{*}{ Variável* } & \multicolumn{2}{c}{ Número de observações } \\
\cline { 2 - 3 } & Ao nascer & Aos 21 dias \\
\hline Número de leitegadas & 335 & 335 \\
Total de leitões & 3259 & 2662 \\
Leitões nascidos/leitegada (média) & 9,72 & - \\
Leitões nascidos vivos & 3095 & - \\
Nascidos vivos/leitegada (média) & 9,24 & - \\
Número de machos & 1607 & 1389 \\
Número de fêmeas & 1488 & 1273 \\
Peso médio do leitão $(\mathrm{kg})$ & 1,35 & 5,11 \\
\hline
\end{tabular}

*Idade média das fêmeas do plantel (anos): 2,07.

Tabela 2. Estatística descritiva para algumas características de leitões da raça Large White

\begin{tabular}{lcccccc} 
Variável & Observações & Média & Desvio padrão & Soma & Mínimo & Máximo \\
\hline Época & 335 & 1,4537 & 0,4985 & 487,00 & 1,00 & 2,00 \\
TL & 335 & 9,7283 & 2,7794 & 3259,00 & 2,00 & 17,00 \\
Idade & 335 & 2,0781 & 1,1244 & 696,19 & 0,84 & 6,25 \\
Idade $^{2}$ & 335 & 5,5793 & 6,7601 & 1869,07 & 0,70 & 39,06 \\
PERCM & 335 & 49,6281 & 17,5839 & 16625,00 & 0,00 & 90,00 \\
PMN & 335 & 1,3500 & 0,1840 & 452,25 & 0,52 & 2,04 \\
\hline $\begin{array}{l}\text { Época } \\
\text { machos; PMN }\end{array}$ & época de parto; TL $=$ tamanho da leitegada; Idade = efeito linear; Idade ${ }^{2}=$ efeito quadrático; PERCM = percentual de \\
\end{tabular}


Tabela 3. Coeficiente de correlação simples e respectivo nível de probabilidade das variáveis analisadas em leitões da raça Large White

\begin{tabular}{lcccccc} 
Variável & Época & TL & Idade & Idade $^{2}$ & PERCM & PMN \\
\hline Época & 1,00000 & 0,2223 & $-0,00691$ & 0,00505 & 0,12499 & $-0,04331$ \\
$($ Prob $>|t|)$ & 0,0 & 0,6852 & 0,8998 & 0,9267 & 0,0221 & 0,4295 \\
TL & & 1,00000 & 0,07922 & 0,02110 & $-0,06352$ & $-0,28462$ \\
$($ Prob $>|t|)$ & 0,0 & 0,1479 & 0,7004 & 0,2463 & 0,0001 \\
Idade & & & 1,00000 & 0,96881 & $-0,01103$ & 0,06847 \\
$($ Prob $>|t|)$ & & 0,0 & 0,0001 & 0,8406 & 0,2113 \\
Idade $^{2}$ & & & 1,00000 & 0,00385 & 0,05905 \\
$($ Prob $>|t|)$ & & & 0,0 & 0,9441 & 0,2812 \\
PERCM & & & & 1,00000 & 0,04425 \\
$($ Prob $>|t|)$ & & & & 0,0 & 0,4195 \\
PMN & & & & & 1,00000
\end{tabular}

(Prob> $|\mathrm{t}|)$

0,0

Época $=$ época de parto; $\mathrm{TL}=$ tamanho da leitegada; Idade $=$ efeito linear; Idade $^{2}=$ efeito quadrático; PERCM $=$ percentual de machos; $\mathrm{PMN}=$ peso médio ao nascer.

Apenas o efeito da idade da matriz ao parto $(0,84$ a 6,25 anos), como efeito quadrático, determinou modificações no tamanho das leitegadas $(\mathrm{P}<0,01)$. Por derivação matemática, foi determinada a idade da porca que maximiza esse efeito, que foi de 3,12 anos de idade. Maiores leitegadas foram observadas em fêmeas de $2,84 \mathrm{a}$ 3,84 anos de idade, quinta e sexta ordens de parição, dentro dos limites observados por Dierckx et al. (1996) e Pinheiro et al. (1996a).

Quanto à influência materna, a idade da matriz exerceu efeito direto sobre o tamanho da leitegada. A elevação da prolificidade com o aumento da idade da fêmea teve influência indireta sobre o peso individual do leitão ao nascer, assumindo importância considerável sobre as características de variabilidade da leitegada, o que também foi observado por Freitas et al. (1992). A determinação do efeito da idade da matriz ao parto é valiosa para o estabelecimento do manejo de eliminação de fêmeas, condicionando sua permanência no plantel de reprodução. O fato de a idade ter apresentado efeito quadrático sobre o tamanho da leitegada não significa que porcas com idade abaixo de 2,84 ou acima de 3,84 anos devam ser eliminadas, entretanto observou-se que esse intervalo é o que determina melhores desempenhos.

Com relação ao efeito da época de nascimento, o fato de os leitões nascerem em épocas distintas não determinou influência sobre o tamanho da leitegada $(\mathrm{P}>0,05)$.
A temperatura variou de 24,0 a $30,6^{\circ} \mathrm{C}$ e de 24,8 a $30,5^{\circ} \mathrm{C}$ nas épocas chuvosa e seca, respectivamente, permanecendo próxima da variação térmica da faixa de conforto de 16 a $27^{\circ} \mathrm{C}$ (Mores, 1993) para porcas cobertas (período de implantação embrionária e final da gestação), não influenciando, possivelmente, na mortalidade de embriões ou na reabsorção de fetos e não determinando modificações no tamanho da leitegada ao nascer (Holanda et al., 2000).

O peso médio ao nascer foi de $1,35 \pm 0,18 \mathrm{~kg}$, média considerada como ideal pela literatura, que varia de 1,18 a 1,45kg (Martins et al., 1998; Sobestiansky et al., 1998).

Para peso médio ao nascer, foram significativas apenas duas das três variáveis estudadas: a idade da matriz ao parto e o tamanho da leitegada. A idade da matriz ao parto, como efeito linear $(\mathrm{P}<0,05)$, determinou associação positiva com peso dos leitões ao nascer, indicando que o aumento da idade da fêmea imprimiu aos leitões maior peso individual no momento do parto. Este resultado difere dos obtidos por Fonseca et al. (1988) e Pinheiro et al. (1996b), que encontraram efeito quadrático da idade da matriz e/ou ordem de parto sobre o peso dos leitões ao nascer. A observação apenas do efeito linear para essa variável pode ter sido em função da composição do plantel, formado por maior número de fêmeas novas com idade média de 2,07 anos e da pequena quantidade de fêmeas que compunham a faixa etária de maior produtividade $(2,84$ a 3,84 anos). 
Com relação ao tamanho da leitegada, o efeito sobre o peso médio ao nascer foi significativo $(\mathrm{P}<0,001)$. Para cada leitão adicional, houve redução de $20 \mathrm{~g}$ no peso médio ao nascer, verificado a partir da equação $\hat{\mathrm{Y}}_{\mathrm{i}}=1,466114$ $0,011458 \mathrm{X}_{1}+0,078122 \mathrm{X}_{2}-0,010797 \mathrm{X}_{3}$ $0,020748 X_{4}$. Essa redução foi semelhante à observada por Schlindwein et al. (1979), de 18g, no peso individual para cada leitão adicional. Com isso, pôde-se constatar que leitegadas de 9 a 12 leitões apresentaram peso individual médio em torno de $1,3 \mathrm{~kg}$, acima, portanto, da faixa crítica de peso para leitões ao nascer. Este resultado significativo do tamanho da leitegada sobre o peso médio ao nascer confirma os obtidos por Munari (1991) e Mores (1993), ao constatarem que leitegadas numerosas ao nascer, com baixo peso individual, influenciam a produção de leitões fracos e menos ativos, aumentando o índice de mortalidade prédesmame.

Não se observou efeito da época de parição $(\mathrm{P}>0,05)$ sobre o peso médio ao nascer. Segundo Mores (1993), variações na temperatura ambiente superiores a $6^{\circ} \mathrm{C}$ são suficientes para limitar a produção de leitões na maternidade. As variações térmicas observadas, de $6,6^{\circ} \mathrm{C}$ e $5,7^{\circ} \mathrm{C}$ nas épocas seca e chuvosa, respectivamente, não causaram transtornos de ambiência e, conseqüentemente, metabólicos para as fêmeas no período de gestação.

O peso médio aos 21 dias foi de $5,06 \pm 1,00 \mathrm{~kg}$. O número de nascidos vivos ( 2 a 15 leitões) teve efeito $(\mathrm{P}<0,01)$ sobre o peso aos 21 dias, pois, para cada leitão nascido vivo, houve decréscimo de $62 \mathrm{~g}$ no peso médio do leitão aos 21 dias de idade, determinando associação negativa entre a variável causal e a variável resposta pela equação $\hat{\mathrm{Y}}_{\mathrm{i}}=5,5928+0,00055 \mathrm{X}_{1}-0,0281 \mathrm{X}_{2}-0,0624 \mathrm{X}_{3}$ $+0,0018 X 4$. De acordo com Alves et al. (1987), as variações nos pesos de leitegadas aos 21 dias de idade são causadas, principalmente, pelas variações no seu tamanho e, segundo Van Der Lender e Jager (1991), esse é o fator de maior influência sobre o crescimento dos leitões até a desmama.

Não se verificou efeito da época de parto sobre o peso médio aos 21 dias $(\mathrm{P}>0,05)$ e, independente da época de nascimento, nenhuma interferência foi notada, mesmo com amplitudes térmicas em torno de $9^{\circ} \mathrm{C}$. Isso pode ser explicado pelo ambiente em que o leitão permaneceu até os 21 dias de idade. Nas celas de parição, onde permaneciam junto à porca, os leitões, provavelmente, foram submetidos a condições favoráveis ao seu desenvolvimento, com temperaturas muito próximas da faixa de conforto térmico $\left(29\right.$ a $\left.31^{\circ} \mathrm{C}\right)$, sugerida por Naãs (1987). Resultado semelhante foi obtido por Pinheiro et al. (1996b).

O percentual de machos na leitegada (de 0 a $90 \%$ ) também não apresentou efeito sobre o peso médio aos 21 dias $(\mathrm{P}>0,05)$. Fireman (1994) e Fireman et al. (1996) observaram que o peso elevado ao nascer tem maior importância para a sobrevivência dos machos do que para a das fêmeas, visto que elas reagem melhor ao aumento de peso. Neste trabalho, apenas o percentual de machos na leitegada não foi suficiente para determinar efeito significativo.

Não há relatos, na literatura consultada, de como a diferença entre sexos e/ou percentual de machos na leitegada ao nascer influenciaria o peso do leitão aos 21 dias de idade e ao desmame. Possivelmente, tanto o tamanho da leitegada como o peso médio do leitão são influenciados pelo meio com maior evidência, não sendo o percentual de machos na leitegada, como variável única, suficiente para determinar aumento do peso médio da leitegada aos 21 dias.

Não houve efeito da idade da matriz ao parto sobre o peso médio aos 21 dias de idade $(\mathrm{P}>0,05)$. Não foi possível estabelecer correlação da idade da matriz com o peso dos leitões aos 21 dias de idade, ao contrário do que observaram Schlindwein et al. (1980), sobre o peso dos leitões ao nascer, e Pinheiro et al. (1996b), sobre o peso aos 21 dias de idade.

\section{CONCLUSÕES}

A idade da matriz determinou mudanças no tamanho da leitegada, isto é, maior leitegada poderá ser obtida em fêmeas de 2,5 a 4,0 anos de idade. O tamanho de leitegada e a idade da matriz devem ser levados em consideração na avaliação do peso ao nascer, visto que pode haver redução do peso médio ao nascer para cada leitão adicional e maior peso individual ao nascimento, com o aumento da idade da fêmea ao parto. Quanto ao peso médio aos 21 dias de idade, apenas o número de leitões nascidos vivos 
deve ser considerado na sua avaliação, pois maior número de nascidos vivos induz ao maior peso médio da leitegada, com redução no peso médio de cada leitão.

\section{REFERÊNCIAS BIBLIOGRÁFICAS}

ALVES, R.G.O; SILVA, M.A.; PEREIRA, J.A.A. et al. Influência de fatores de meio e genéticos no tamanho e peso da leitegada ao nascer e aos 21 dias em suínos. Rev. Soc. Bras. Zootec., v.16, p.540-549, 1987.

ANUÁRIO Estatístico do Brasil. Rio de Janeiro: IBGE, Seção 3, p.69.

ASSOCIAÇÃO BRASILEIRA DOS CRIADORES DE
SUÍNOS, $2003 . \quad$ Disponível $<$ http://www.abcs.com.br/>. Acessado em 2 setembro 2003.

DIERCKX, S.M.A.G.; RAMOS, A.A.; NUNES, J.R.V. Estudo de fatores de meio sobre características de leitegada em suínos. 1: Tamanho de leitegada. Vet. Zootec., v.8, p.99-106, 1996.

FIREMAN, F.A.T. Fatores que influenciam a natimortalidade e a mortalidade de leitões até 21 dias de idade. 1994. 70f. Dissertação (Mestrado) - Universidade Federal de Pelotas, Pelotas, RS.

FIREMAN, F.A.T.; SIEWERDT, F.; FIREMAN, A.K.B.A.T. Efeito do tamanho da leitegada sobre a natimortalidade e mortalidade dos leitões Large White do nascimento até 21 dias de idade. Arch. Latioam. Prod. Anim., v.4, p.83-90, 1996.

FONSECA, N.A.N.; MILAGRES, J.C.; PEREIRA, J.A.A. et al. Produtividade de porcas mestiças em uma exploração comercial em Jequeri, Minas Gerais. III: Ganhos de peso do leitão e da leitegada. Rev. Soc. Bras. Zootec., v.17, p.85-91, 1988.

FREITAS, R.T.; OLIVEIRA, A.I.G.; LIMA, J.A.F. et al. Estudo de características produtivas em matrizes de criações de suínos no sul do estado de Minas Gerais. Rev. Soc. Bras. Zootec., v.21, p.186 -199, 1992.

GOMES, M.F.M.; GIROTTO, A.F.; TALAMINI, D.J.D. et al. Análise prospectiva do complexo agroindustrial de suínos no Brasil. Concórdia: EMBRAPA - CNPSA, 1992. 108p. (Documentos, 26).

HOLANDA, M.C.R.; BARBOSA, S. B.P.; AZEVEDO, $M$. et al. Natimortalidade e mortalidade até 21 dias de idade de leitões da raça Large White. Rev. Soc. Bras. Zootec., v.29, Supl. p.2276-2282, 2000.

MARTINS, T.D.D.; SILVA, M.B.; LIMA, P.C. et al. Influência do peso da porca no dia do parto sob o peso e número de leitões nascidos vivos. In: CONGRESSO NORDESTINO DE PRODUÇÃO ANIMAL, 6., 1998, Fortaleza. Anais... Fortaleza, 1998. v.2, p.196.

MORES, N. Fatores que limitam a produção de leitões na maternidade. In: SUINOCULTURA dinâmica. Concórdia: EMBRAPA - CNPSA, 1993. v.2. 5p.
MUNARI, J.L.P. Manejo da fêmea suína durante o parto e a lactação. In: CONGRESSO BRASILEIRO DE REPRODUÇÃO ANIMAL, 9., 1991, Belo Horizonte. Anais..., Belo Horizonte, 1991. v.2, p.164 - 171.

NAÃS, I.A. Eficiência das edificações na suinocultura intensiva. Santa Catarina: Associação Brasileira de Veterinários Especialistas em Suínos, 1987. 9p. (Boletim Técnico, 1).

PINHEIRO, M.J.P.; GALVÃO, R.J.D.; BARBOSA NETO, F. et al. Características reprodutivas de suínos puros na região Semi-árida do Rio Grande do Norte. I. Tamanho da leitegada. In: REUNIÃO ANUAL DA SOCIEDADE BRASILEIRA DE ZOOTECNIA, 33., 1996, Fortaleza. Anais... Fortaleza: SBZ, 1996a. v.1, p.404-406.

PINHEIRO, M.J.P.; GALVÃO, R.J.D.; BARBOSA NETO, F. et al. Características reprodutivas de suínos puros na região Semi-árida do Rio Grande do Norte. II. Pesos de leitões e leitegadas. In: REUNIÃO ANUAL DA SOCIEDADE BRASILEIRA DE ZOOTECNIA, 33., 1996, Fortaleza. Anais... Fortaleza: SBZ, 1996b. v.1, p.407-409.

SCHLINDWEIN, A.P.; DUARTE, F.A.M. Influências de fatores não genéticos na variabilidade de características de leitegadas em suínos da raça Duroc. In: REUNIÃO I CONGRESSO BRASILEIRO DE ZOOTECNIA E REUNIÃO ANUAL DA SOCIEDADE BRASILEIRA DE ZOOTECNIA, 17., 1980, Fortaleza. Anais... Fortaleza: SBZ, 1980. v.1, p.247.

SCHLINDWEIN, A.P.; TORRES, J.R.; CARNEIRO, G.G. Efeitos de fatores de ambiente sobre o número de leitões nascidos por leitegada e peso individual ao nascimento em suínos da raça Duroc. Arq. Esc. Vet. $U F M G$, v.31, p.155-167, 1979.

SIEWERDT, F.; RECH, J.L. Relações biológicas entre caracteres de leitegadas produzidas por suínos das raças Landrace e Large White. Rev. Soc. Bras. Zootec., v.20, p.144-152, 1991

SIMPLÍCIO, B.J.; LINS, F.A.A.; SIMPLÍCIO, B.J. Estudo de alguns parâmetros produtivos e reprodutivos de suínos no estado da Paraíba - ganho de peso do leitão e tamanho da leitegada. In: REUNIÃO ANUAL DA SOCIEDADE BRASILEIRA DE ZOOTECNIA, 27., 1990, Campinas. Anais... Campinas: SBZ, 1990. v.1, p. 435.

SOBESTIANSKY, J.; WENTS, I.; SILVEIRA, P.R.S. et al. Suinocultura intensiva: produção, manejo e saúde do rebanho. Brasília: EMBRAPA-SPI; Concórdia: EMBRAPA-CNPSA, 1998. 388p.

SOFTWARE: changes and enhancements through release 6.11. Cary, NC: SAS Institute, 1996. 1104p.

VAN DER LENDER, T.; JAGER, D. Death risk and preweaning growth rate of piglets in relation to the within-litter weight distribution at birth. Liv. Prod. Sci., v.28, p.73-84, 1991 